\section{Faktor-Faktor Yang Mempengaruhi Tingkat Kebangkrutan Perbankan Syariah Periode 2013-2019}

Studi Kasus Pada Bank BRI Syariah, BTN Syariah, BCA Syariah, Bank Syariah

Mandiri, Bank BNI Syariah

\author{
Oktia Vandriani Alyana ${ }^{1^{*}}$ dan Aang Munawar ${ }^{2}$ \\ ${ }^{1,2}$ Program Studi Manajemen, Institut Bisnis dan Informatika Kesatuan \\ *email: oktiavandriani@gmail.com
}

Determinants of

Sharia Bank's

Bankruptcy Rate

115

Submitted:

\begin{abstract}
This research was conducted using banking financial statements for seven years, namely the period 2013 - 2019 from banks engaged in the financial sector. The analytical method used is financial ratio analysis By using financial ratio analysis, it can be seen that the LDR, NPL, CAR and NIM affect the level of bankruptcy in banks this can occur due to internal factors contained in a bank. Then the conclusion is that the LDR, NPL, CAR and NIM affect the bank's bankruptcy level. It can be seen in the financial statements of the results of the LDR, NPL, CAR and NIM produced by banks increasing and decreasing during the research period, this has caused the bankruptcy rate of banks to also increase and decrease. The banking industry tries to maintain its Z-score by maintaining the value of the LDR, NPL, CAR and NIM variables on the financial statements, although the factors produced are not too large and even below average, the factors have increased. The number of factors in the financial statements that are affected by the level of financial ratios and income that has decreased due to banks that have not been able to emphasize their income. Banks conduct policies well by maintaining health and profit growth in terms of financial statements.
\end{abstract}

Keywords: LDR, NPL, CAR, NIM and Bank's Bankruptcy Rate
FEBRUARI 2021

Accepted: MARET 2021

\begin{abstract}
ABSTRAK
Penelitian ini dilakukan dengan menggunakan laporan keuangan perbankan selama tujuh tahun yaitu periode 2013 - 2019 dari perbankan yang bergerak dibidang sektor keuangan. Metode analisis yang digunakan adalah analisis rasio keuangan. Dengan menggunakan analisis rasio keuangan, maka dapat diketahui bahwa LDR, NPL, CAR dan NIM berpengaruh terhadap tingkat kebangkrutan pada perbankan hal ini dapat terjadi karena adanya faktor internal yang terdapat pada sebuah perbankan. Maka diperoleh kesimpulan bahwa LDR, NPL, CAR dan NIM berpengaruh terhadap tingkat kebangkrutan bank. Dapat dilihat pada laporan keuangan hasil dari LDR, NPL, CAR dan NIM yang dihasilkan perbankan meningkat dan menurun pada periode penelitan, hal ini menyebabkan tingkat kebangkrutan perbankan juga mengalami peningkatan dan penurunan. Perbankan mencoba untuk mempertahankan nilai $\mathrm{Z}$ - score nya dengan mempertahankan nilai variabel - variabel LDR, NPL, CAR dan NIM terhadap laporan keuangan, walaupun faktor - faktor yang dihasilkan tidak terlalu besar dan bahkan di bawah rata - rata namun faktor -faktor nya mengalami peningkatan. Jumlah faktor faktor pada laporan keuangan yang dipengaruhi dari tingkat rasio keuangan dan pendapatan yang mengalami penurunan hal tersebut dikarenakan perbankan yang belum mampu menekankan pendapatannya. Perbankan melakukan kebijakan dengan baik yaitu dengan mempertahankan kesehatan dan pertumbuhan laba dari sisi laporan keuangan.
\end{abstract}

Kata Kunci : LDR, NPL, CAR, NIM dan Tingkat Kebangkrutan Bank

\section{JIMKES} SSN $2721-169 \mathrm{X}$ 
Determinants of

Sharia Bank's

Bankruptcy Rate

116

\section{PENDAHULUAN}

Suatu perekonomian di suatu negara ditentukan oleh banyak faktor, salah satunya adalah sektor perbankan yang mempunyai tugas utama sebagai lembaga penghimpun dan penyalur dana masyarakat. Bank dapat dikatakan sebagai penggerak utama roda perekonomian karena perannya sebagai alternatif sumber modal guna menggerakkan sektor riil, mendanai proyek negara dan juga membiayai kebutuhan masyarakat pada umumnya. Industri perbankan selama beberapa kurun waktu belakangan mengalami perkembangan yang pesat. Bank dianggap sebagai penggerak roda perekonomian suatu negara. Hal ini dikarenakan fungsi bank sebagai lembaga keuangan sangat penting, misalnya dalam peredaraan uang guna menunjang kegiatan usaha, tempat menyimpan uang, melakukan pembayaran atau penagihan, pembiayaan, dan masih banyak jasa keuangan lainnya (Kamal, 2012). Untuk mempertahankan suatu sistem keuangan, sebuah bank harus dapat berkompetisi dengan bank-bank kompetitor dan lembaga penyedia jasa keuangan lainnya yang juga memberikan layanan jasa keuangan.

Guna mengantisipasi hadirnya kesulitan keuangan pada bank, perlu dikembangkan suatu sistem yang dapat memberikan peringatan dini (early warning) adanya problem keuangan yang mengancam kelangsungan operasional bank. Potensi kebangkrutan yangterdeteksi dini akan memungkinkan pihak manajemen memberikan penanganan korektif agar dapat memulihkan kondisi keuangan perusahaan dari krisis. Salah satu indikator yang digunakan untuk mengukur tingkat kesulitan bank yaitu menggunakan Model Altman's Z-score. Menurut Syaryadi (2012) Z score merupakan model yang memberikan rumus untuk menilai kapan perusahaan akan bangkrut. Semakin besar peluang munculnya Financial Distress semakin besar pula ancaman bank mengalami kebangkrutan tersebut dan semakin jelek pula posisi bank tersebut dari segi penggunaan aset. Sedangkan rasio keuangan yang mempengaruhi tingkat kebangkrutan antara lain Non Performing Loan (NPL), Capital Adequacy Ratio (CAR), dan Loan to Deposit Ratio (LDR) dan Net Interest Margin (NIM).

Tujuan penelitian adalah : (1) Mengetahui pengaruh variabel LDR terhadap tingkat kebangkrutan pada perbankan, (2) Mengetahui pengaruh variabel NPL terhadap tingkat kebangkrutan pada perbankan, (3) Mengetahui pengaruh variabel CAR terhadap tingkat kebangkrutan pada perbankan, (4) Mengetahui pengaruh variabel NIM terhadap tingkat kebangkrutan pada perbankan, (5) Mengetahui pengaruh keseluruhan variabel terhadap tingkat kebangkrutan pada perbankan

\section{METODOLOGI PENELITIAN}

Jenis penelitian ini menggunakan penelitian eksplanatif, di mana dalam penelitian ini mengidentifikasikan suatu hubungan sebab akibat dari satu atau lebih variabel dependen dengan manipulasi variabel independent. Lokasi dalam penelitian ini dilakukan di salah satu Bank dari 10 Bank yang akan diteliti di mana dalam memperoleh data, peneliti mengambil dari berbagai situs resmi perbankan dengan populasi sebanyak 5 Bank yang terdiri dari Bank Syariah yang ada di Indonesia yang telah terdaftar di OJK periode tahun 2013-2019. Dalam penelitian ini yang menjadi populasi adalah sektor Perbankan Syariah selama penelitian ini dilakukan. Sampel dalam penelitan ini yaitu Perbankan Syariah yang berada di Indonesia. Seperti Bank Syariah yang terdaftar di OJK, beberapa yang masuk kedalam Bank Umum Syariah (BUS) yaitu Bank Rakyat Indonesia Syariah (BRI Syariah), Bank Tabungan Negara Syariah (BTN Syariah), PT Bank BCA Syariah, PT. Bank Syariah Mandiri, PT. Bank BNI Syariah.

Data-data yang dikumpulkan oleh penulis yang kemudian diolah dan dianalisa sesuai dengan tujuan penulis, jenis-jenis data yang digunakan adalah data kuantitatif, sedangkan sumber data yang digunakan adalah data primer dan data sekunder. Metode atau cara untuk mengolah sebuah data menjadi informasi sehingga karakteristik data tersebut menjadi mudah untuk dipahami dan juga bermanfaat untuk menemukan solusi permasalahan, yang terutama adalah masalah yang tentang sebuah penelitian. Penelitian ini menggunakan analis.is Statistik Deskriptif dengan tujuan untuk menganalisis suatu 
data kuantitatif dengan harapan dapat mencerminkan suatu data tersebut. Adapun data analisisnya dalam penelitian ini adalah perusahaan yang menjadi sampel yaitu perusahaan perbankan. Dengan digunakannya data statistik maka hendak didapat suatu nilai rata-rata, nilai terendah, nilai tertinggi dan juga nilai distribusi frekuensi.

Dalam penelitian ini uji hipotesisnya dengan menggunakan uji regresi logistik (logistic regression) karena dalam penelitian ini hanya memiliki satu variabel dependen yang non metrik (nominal) serta memiliki variabel independent yang lebih dari satu. Jadi regresi logistik ini umumnya dipakaijika asumsi multivariate distribution tidak dipenuhi. Dalam penelitian ini hanya memiliki satu variabel dependen yang non metrik (nominal) serta memiliki variabel independent yang lebih dari satu. Analisis koefisien korelasi dilakukan untuk mempelajari apakah ada hubungan antara dua variabel atau lebih, sedang analisis regresi memprediksi seberapa jauh pengaruh tersebut Secara spesifik, tujuan analisis korelasi adalah ingin mengetahui apakah di anara dua variabel terdapat hubungan, dan jika terdapat hubungan, bagaimana arah hubungan dan seberapa besar hubungan tersebut. Secara teoretis, dua variabel dapat sama sekali tidak berhubungan $(r=0)$, berhubungan secara sempurna $(\mathrm{r}=1)$, atau antara kedua angka tersebut. Arah korelasi juga dapat positif (berhubungan searah) atau negatif (berhubungan berlainan arah).

Berdasarkan teori diatas maka dapat disusun hipotesis sebagai berikut:

$\mathrm{H}_{0}$ : Diduga tidak ada pengaruh antara variabel $\mathrm{X}$ dan $\mathrm{Y}$

$\mathrm{H}_{1}$ : Diduga ada pengaruh LDR terhadap Tingkat Kebangkrutan Bank

$\mathrm{H}_{2}$ : Diduga ada pengaruh NPL terhadap Tingkat Kebangkrutan Bank

$\mathrm{H}_{3}$ : Diduga ada pengaruh CAR terhadap Tingkat Kebangkrutan Bank

$\mathrm{H}_{4}$ : Diduga ada pengaruh NIM terhadap Tingkat Kebangkrutan Bank

$\mathrm{H}_{5}$ : Diduga ada pengaruh bersama-sama LDR, NPL, CAR, dan NIM terhadap Tingkat

Kebangkrutan Bank

\section{HASIL DAN PEMBAHASAN}

Berdasarkan tujuan penelitian, maka dibawah ini penulis akan menguraikan hasil penelitian yang berkaitan dengan faktor-faktor yang mempengaruhi tingkat kebangrutan suatu perbankan. Adapun data yang penulis gunakan untuk penelitian ini ialah laporan keuangan tahunan yang terdaftar di Otoritas Jasa Keuangan (OJK) periode 2013-2019. Data yang digunakan bersumber dari 5 bank, yaitu : PT. Bank BRI Syariah, PT. Bank Tabungan Negara Syariah, PT. Bank BCA Syariah, PT. Bank Syariah Mandiri dan PT. Bank BNI Syariah

Tabel 1. Pergerakan Loan to Deposit Ratio Pada Setiap Bank

\begin{tabular}{|c|c|c|c|c|c|}
\hline TAHUN & $\begin{array}{c}\text { LDR BTN } \\
\text { SYARIAH }\end{array}$ & $\begin{array}{c}\text { LDR BRI } \\
\text { SYARIAH }\end{array}$ & $\begin{array}{c}\text { LDR BCA } \\
\text { SYARIAH }\end{array}$ & $\begin{array}{c}\text { LDR BANK } \\
\text { SYARIAH } \\
\text { MANDIRI }\end{array}$ & $\begin{array}{c}\text { LDR BNI } \\
\text { SYARIAH }\end{array}$ \\
\hline 2013 & $104,42 \%$ & $102,70 \%$ & $83,50 \%$ & $89,37 \%$ & $97,86 \%$ \\
\hline 2014 & $108,86 \%$ & $93,90 \%$ & $91,20 \%$ & $82,13 \%$ & $92,58 \%$ \\
\hline 2015 & $108,78 \%$ & $84,16 \%$ & $91,40 \%$ & $81,99 \%$ & $91,94 \%$ \\
\hline 2016 & $102,66 \%$ & $81,47 \%$ & $90,70 \%$ & $79,19 \%$ & $84,57 \%$ \\
\hline 2017 & $103,13 \%$ & $71,87 \%$ & $88,50 \%$ & $77,66 \%$ & $80,21 \%$ \\
\hline 2018 & $112,83 \%$ & $75,49 \%$ & $89,00 \%$ & $77,25 \%$ & $79,62 \%$ \\
\hline 2019 & $111,54 \%$ & $80,12 \%$ & $90,98 \%$ & $75,55 \%$ & $74,31 \%$ \\
\hline
\end{tabular}

Sumber : Data Sekunder Diolah

\section{Analisis Loan to Deposit Ratio (LDR)}

LDR atau Loan to Deposit Ratio ialah rasio yang digunakan untuk mengukur kemampuan bank dalam memenuhi kewajiban jangka pendek (bisa disebut likuiditas) dengan membagi total kredit terhadap total Dana Pihak Ketiga (DPK). Likuiditas perbankan perlu dikelola guna memenuhi kebutuhan saat nasabah mengambil dananya dan menyalurkan pinjaman (kredit) kepada peminjam (debitur). Jika nilai LDR terlalu tinggi, artinya perbankan tidak memiliki likuiditas yang cukup memadai untuk menutup kewajibannya terhadap nasabah (DPK). Sebaliknya, jika nilai LDR terlalu rendah berarti
Determinants of

Sharia Banks'

Bankruptcy Rate

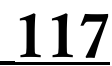


Determinants of Sharia Bank's Bankruptcy Rate perbankan memiliki likuiditas yang cukup memadai tetapi mungkin pendapatannya lebih rendah, karena seperti yang diketahui dunia perbankan memperoleh pendapatan melalui kredit yang disalurkan. LDR dapat dihitung dengan cara:

$$
\mathrm{LDR}=\frac{\text { Total Kredit kepada pihak ketiga bukan Bank }}{\text { Total Dana Pihak Ketiga }} \times 100 \%
$$

\section{Analisis Non Performing Loan (NPL)}

Rasio ini membuktikan bagaimana kinerja suatu manajemen dalam bank untuk mengolah pinjaman bermasalah yang diserahkan oleh pihak bank. Dengan ini dimaksudkan kredit adalah kredit yang diserahkan ke selain kredit terhadap pihak ketiga (bank lain). Kredit bermasalah merupakan pinjaman atas kualitas yang kurang baik, adapun rumus NPL seperti berikut : NPL $=$ Total NPLTotal kredit $x 100 \%$

Tabel 2. Pergerakan NPL Pada Perbankan Syariah periode 2013-2019

\begin{tabular}{|c|c|c|c|c|c|}
\hline TAHUN & $\begin{array}{c}\text { NPL BTN } \\
\text { Syariah }\end{array}$ & $\begin{array}{c}\text { NPL BRI } \\
\text { Syariah }\end{array}$ & $\begin{array}{c}\text { NPL BCA } \\
\text { Syariah }\end{array}$ & $\begin{array}{c}\text { NPL Bank } \\
\text { Syariah Mandiri }\end{array}$ & $\begin{array}{c}\text { NPL BNI } \\
\text { Syariah }\end{array}$ \\
\hline 2013 & $3,04 \%$ & $3,26 \%$ & $0,10 \%$ & $2,29 \%$ & $1,13 \%$ \\
\hline 2014 & $2,79 \%$ & $3,65 \%$ & $0,10 \%$ & $4,29 \%$ & $1,04 \%$ \\
\hline 2015 & $2,11 \%$ & $3,89 \%$ & $0,50 \%$ & $4,05 \%$ & $1,46 \%$ \\
\hline 2016 & $1,85 \%$ & $3,19 \%$ & $0,20 \%$ & $3,13 \%$ & $1,64 \%$ \\
\hline 2017 & $1,66 \%$ & $4,72 \%$ & $0,28 \%$ & $2,71 \%$ & $1,50 \%$ \\
\hline 2018 & $1,99 \%$ & $4,97 \%$ & $0,30 \%$ & $1,56 \%$ & $1,52 \%$ \\
\hline 2019 & $2,33 \%$ & $3,38 \%$ & $0,26 \%$ & $1,00 \%$ & $1,44 \%$ \\
\hline
\end{tabular}

Sumber: Data Sekunder Diolah

Analisis Capital Adequacy Ratio (CAR)

Rasio CAR ini bertujuan untuk menunjukkan besarnya jumlah aktiva bank yang memiliki unsur risiko seperti pinjaman, surat berharga maupun tagihan pada bank lain (Almilia dan Herdiningtyas, 2005). Rumus rasio ini menurut SE BI No.7/10/DPNP tanggal 31 Maret 2005 yaitu: $\mathrm{CAR}=$ ModalAktiva tertimbang menurut risiko $\times 100 \%$

Tabel 3. CAR Pada Perbankan Syariah periode 2013-2019

\begin{tabular}{|c|c|c|c|c|c|}
\hline TAHUN & $\begin{array}{c}\text { CAR BTN } \\
\text { Syariah }\end{array}$ & $\begin{array}{c}\text { CAR BRI } \\
\text { Syariah }\end{array}$ & $\begin{array}{c}\text { CAR BCA } \\
\text { Syariah }\end{array}$ & $\begin{array}{c}\text { CAR Bank } \\
\text { Syariah Mandiri }\end{array}$ & $\begin{array}{c}\text { CAR BNI } \\
\text { Syariah }\end{array}$ \\
\hline 2013 & $15,62 \%$ & $14,49 \%$ & $22,40 \%$ & $14,10 \%$ & $16,23 \%$ \\
\hline 2014 & $14,57 \%$ & $12,89 \%$ & $29,60 \%$ & $14,76 \%$ & $18,42 \%$ \\
\hline 2015 & $14,69 \%$ & $13,23 \%$ & $34,30 \%$ & $8,16 \%$ & $18,04 \%$ \\
\hline 2016 & $16,54 \%$ & $13,90 \%$ & $36,70 \%$ & $11,60 \%$ & $19,90 \%$ \\
\hline 2017 & $15,99 \%$ & $13,78 \%$ & $29,40 \%$ & $14,01 \%$ & $20,14 \%$ \\
\hline 2018 & $17,55 \%$ & $23,82 \%$ & $24,30 \%$ & $15,50 \%$ & $19,31 \%$ \\
\hline 2019 & $18,05 \%$ & $20,73 \%$ & $5,79 \%$ & $20,19 \%$ & $18,88 \%$ \\
\hline
\end{tabular}

Sumber: Data Sekunder Diolah

\section{Analisis Net Interest Margin (NIM)}

Net Interest Margin atau margin bunga bersih mirip dalam konsep untuk menyebarkan bunga bersih, namun penyebaran bunga bersih adalah selisih rata-rata nominal antara pinjaman dan suku bunga pinjaman, tanpa kompensasi untuk kenyataan bahwa aktiva produktif dan dana yang dipinjam dapat menjadi alat yang berbeda dan berbeda dalam volume. Margin bunga bersih sehingga dapat lebih tinggi (atau kadang-kadang lebih rendah) daripada penyebaran bunga bersih. Perhitungan : NIM = Pendapatan Bunga/ Aktiva Produktif 
Dibawah ini ada tabel data-data NIM Perbankan Syariah periode 2013-2019 yang didapatkan dari laporan keuangan perbankan syariah pada perode tersebut.

Tabel 4. NIM Pada Perbankan Syariah periode 2013-2019

\begin{tabular}{|c|c|c|c|c|c|}
\hline TAHUN & $\begin{array}{c}\text { NIM BTN } \\
\text { Syariah }\end{array}$ & $\begin{array}{c}\text { NIM BRI } \\
\text { Syariah }\end{array}$ & $\begin{array}{c}\text { NIM BCA } \\
\text { Syariah }\end{array}$ & $\begin{array}{c}\text { NIM Syariah } \\
\text { Mandiri }\end{array}$ & $\begin{array}{c}\text { NIM BNI } \\
\text { Syariah }\end{array}$ \\
\hline 2013 & $5,44 \%$ & $6,27 \%$ & $0,10 \%$ & $7,25 \%$ & $9,51 \%$ \\
\hline 2014 & $4,47 \%$ & $6,04 \%$ & $0,80 \%$ & $6,19 \%$ & $9,04 \%$ \\
\hline 2015 & $4,87 \%$ & $1,81 \%$ & $1,00 \%$ & $0,58 \%$ & $0,67 \%$ \\
\hline 2016 & $4,98 \%$ & $0,41 \%$ & $1,24 \%$ & $0,64 \%$ & $0,90 \%$ \\
\hline 2017 & $4,76 \%$ & $-0,12 \%$ & $1,24 \%$ & $0,61 \%$ & $1,50 \%$ \\
\hline 2018 & $4,23 \%$ & $-0,27 \%$ & $1,24 \%$ & $0,96 \%$ & $1,52 \%$ \\
\hline 2019 & $3,41 \%$ & $-0,59 \%$ & $1,24 \%$ & $1,85 \%$ & $1,00 \%$ \\
\hline
\end{tabular}

Sumber: Data Sekunder Diolah

\section{Analisis Statistik Deskriftif}

Dalam penelitian ini diambil data laporan keuangan pada tahun 2013 sampai dengan 2019 dengan sampel sebanyak 5 perusahaan perbankan syariah, maka secara pooled cross sectional diperoleh sejumlah 5 perbankan syariah $\times 7$ tahun $=35$ data observasi. Variabel independen yang digunakan dalam penelitian ini adalah LDR, NPL, CAR, dan NIM, sedangkan variabel dependennya adalah tingkat kebangkrutan pada suatu bank. Data variabel diperoleh melalui perhitungan yang diolah berdasarkan laporan keuangan tahunan yang diperoleh dari BEI atau Laporan Keuangan Perbankan. Analisis statistik deskriptif akan memberikan gambaran atau deskripsi suatu data yang dilihat dari nilai minimum, maksimum, rata-rata (mean), dan standar deviasi yang dihasilkan dari variabel penelitian. Hasil analisis dengan statistik deskriptif menghasilkan data sebagaimana Tabel 5.

Berdasarkan data Tabel 5 semua variabel memiliki nilai rata-rata,nilai minimum, nilai maximum dari variabel $\mathrm{X}$ sampai variabel $\mathrm{Y}$ sudah tertera didalam tabel 4.23. LDR tertinggi pada angka 112,83 pada Bank BTN Syariah tahun 2018 sedangkan untuk LDR terendah pada tahun 2017 pada BRI Syariah tahun 2017 bernilai 71,87. Untuk NPL tertinggi pada Bank BRI Syariah senilai 4,97\% tahun 2018, dan NPL terendah yaitu pada tahun 2013-2014 Bank BCA Syariah. CAR tertinggi dengan angka 36,70 pada Bank BCA Syariah tahun 2016 dan terendah Bank BCA Syariah tahun 2019 sebesar 5,79 dan NIM tertinggi pada tahun 2013 bank Syariah Mandiri sebesar 9,51 dan NIM terendah pada tahun 2019 pada BRI Syariah sebesar -0,59. Untuk financial distress tertinggi di Bank BCA Syariah pada tahun 2019 sebesar 9,60 yang menyatakan bahwa bank sehat dan terendah pada tahun 2014 di BRI Syariah dengan angka 1,38 yang berarti perusahaan dalam tingkat abu-abu atau dalam pengawasan.

Tabel 5. Statistik Deskriptif

\begin{tabular}{|c|c|c|c|c|c|c|}
\hline \multirow{2}{*}{ Var } & $\mathrm{N}$ & Min & Max & \multicolumn{2}{|c|}{ Mean } & $\begin{array}{c}\text { Std. } \\
\text { Deviation }\end{array}$ \\
\cline { 2 - 7 } & Statistic & Statistic & Statistic & Statistic & Std. Error & Statistic \\
\hline LDR & 35 & 71.87 & 112.83 & 89.2983 & 1.95528 & 11.56759 \\
\hline NPL & 35 & .10 & 4.97 & 2.1209 & .24316 & 1.43855 \\
\hline CAR & 35 & 5.79 & 36.70 & 18.2166 & 1.10869 & 6.55908 \\
\hline NIM & 35 & -.59 & 9,51 & 4.8051 & .88133 & 5.21403 \\
\hline FC & 35 & 1.38 & 9.60 & 4.7257 & .38435 & 2.27383 \\
\hline Valid N(listwise) & 35 & & & & & \\
\hline
\end{tabular}

\section{Sumber: Data Primer Diolah}

\section{Uji Kualitas Data}

Uji normalitas bertujuan untuk menguji apakah dalam model regresi, variabel dependen dan variabel independen berdistribusi normal atau berdistribusi tidak normal. Model regresi yang baik adalah distribusi data normal atau mendekati normal. Untuk menguji normalitas data, pada penelitian ini menggunakan metode uji statistik non-
Determinants of

Sharia Banks'

Bankruptcy Rate 
Determinants of Sharia Bank's Bankruptcy Rate parametrik Kolmogorov-Smirnov. Menurut Imam Ghozali (2005), bahwa distribusi data dapat dilihat dengan membandingkan $\mathrm{Z}$ hitung dengan tabel $\mathrm{Z}$ tabel.

Tabel 6. Hasil Uji Normalitas Data

\begin{tabular}{|c|c|c|}
\hline \multicolumn{2}{|c|}{ One-Sample Kolmogorov-Smirnov Test } \\
\hline \multicolumn{2}{|c|}{$\mathrm{N}$} & Unstandardized Residual \\
\hline \multirow{2}{|c|}{$\mathrm{N}$} & 35 \\
\hline Normal Parameters ${ }^{\mathrm{a}, \mathrm{b}}$ & Mean & .0000000 \\
\cline { 2 - 3 } & Std. Deviation & 1.73050738 \\
\cline { 2 - 3 } Most Extreme Differences & Absolute & .096 \\
\cline { 2 - 3 } & Positive & .086 \\
\cline { 2 - 3 } & Negative & -.096 \\
\hline \multicolumn{2}{|c|}{ Test Statistic } & .096 \\
\hline \multicolumn{2}{|c|}{ Asymp. Sig. (2-tailed) } & $.200^{\text {c,d }}$ \\
\hline
\end{tabular}

a. Test distribution is Normal.

b. Calculated from data.

c. Lilliefors Significance Correction.

d. This is a lower bound of the true significance.

Sumber dari data sekunder yang diolah

Hasil pengujian normalitas dengan uji statistik non-parametrik KolmogorovSmirnov menunjukkan bahwa besarnya nilai Kolmogorov-Smirnov adalah 0,096 dan tidak signifikan pada 0,096 . (karena $p=0,096>0,05$ ) yang berarti bahwa residual terdistribusi secara normal.

Uji multikoloniaritas bertujuan untuk menguji apakah dalam model regresi ditemukan adanya korelasi antar variabel bebas. Model regresi yang baik atau standar seharusnya tidak terjadi korelasi antara variabel bebas. Ketentuan yang digunakan untuk nilai VIF adalah apabila nilai VIF $>10$ maka artinya terjadi multikolinieritas dalam model regresi dan sebalikanya jika $\mathrm{VIF}<$ maka artinya tidak terjadi multikolinieritas.

Tabel 7. Hasil Uji Multikolinearitas

\begin{tabular}{|c|c|c|c|}
\hline \multirow{2}{*}{\multicolumn{2}{|c|}{ Variables }} & \multicolumn{2}{|c|}{ Collinearity Statistics } \\
\hline & & Tolerance & VIF \\
\hline \multirow{5}{*}{1} & (Constant) & & \\
\hline & LDR & .935 & 1.070 \\
\hline & NPL & .677 & 1.478 \\
\hline & CAR & .620 & 1.612 \\
\hline & NIM & .865 & 1.157 \\
\hline
\end{tabular}

Dari data diatas bisa kita lihat bahwa dari semua variabel ini menunjukkan tidak ada variabel independen yang memiliki nilai tolerance kurang dari 0,1 dan nilai variance inflation factor (VIF) dari setiap variabel independen di bawah 10. Hal ini menunjukkan bahwa tidak ada variabel independen yang memiliki nilai VIF lebih dari 10, dengan demikian dapat disimpulkan bahwa tidak ada multikolonieritas antara variabel independen dalam model regresi.

Uji Heteroskedastisitas bertujuan untuk menguji apakah dalam model regresi terjadi ketidaksamaan variance dari residual satu pengamatan ke pengamatan yang lain. Jika variance dari residual satu pengamatan ke pengamatan lain tetap, maka disebut homoskedastisitas dan jika berbeda disebut heteroskedastisitas. Model regresi yang baik adalah yang homoskedastisitas atau tidak terjadi heteroskedastisitas. Pada penelitian ini digunakan uji Scatterplot untuk mendeteksi ada atau tidaknya heteroskedastisitas.

Dari hasil uji multikolinearitas menggunakan uji glejser hasil signifikansi dari variabel bebas atau variabel $\mathrm{X}$ ada yang menunjukan data dibawah dari nilai signifikansi 0,05 sehingga dapat disimpulkan bahwa tidak terjadi masalah heterokedastisitas. Dibawah telah diberikan pula uji Scatterplot seperti gambar 2. Dari output ga bar tersebut dapat diketahui bahwa titik-titik tidak membentuk pola yang jelas, dan titik-titik menyebar diatas dan dibawah angka 0 pada sumbu Y. Jadi dapat disimpulkan bahwa tidak terjadi masalah heteroskedastisitas dalam model ini. 


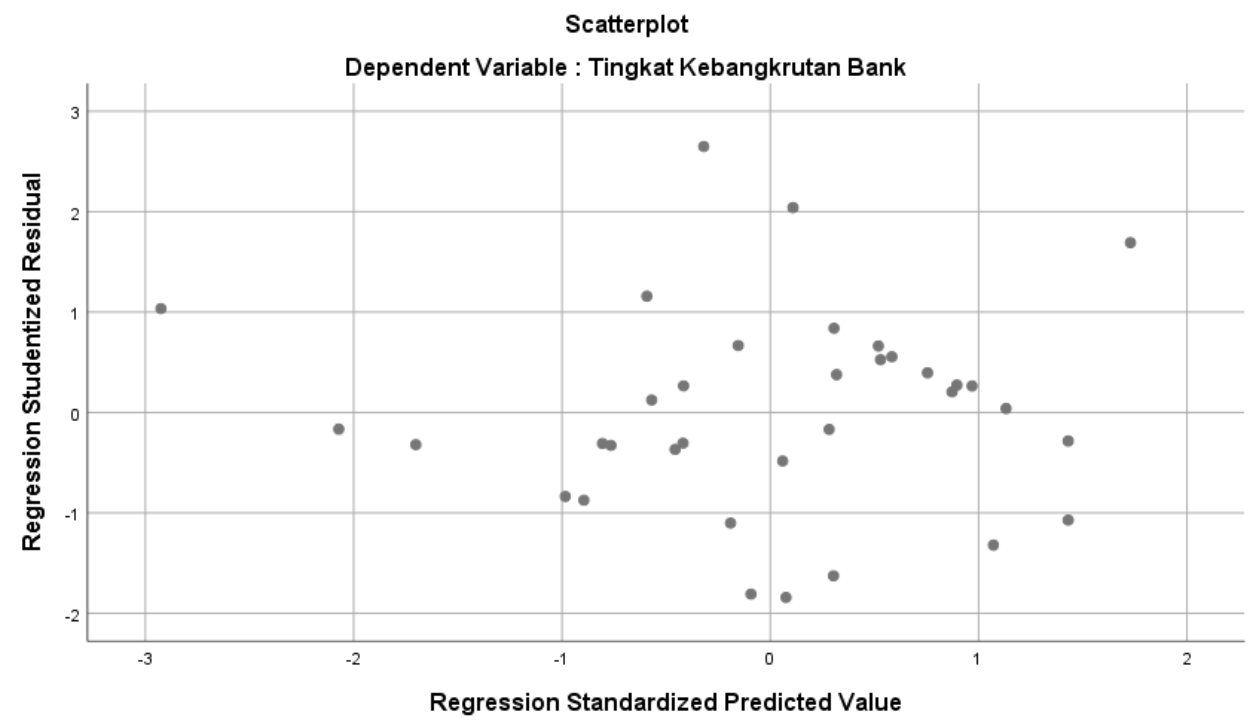

Determinants of

Sharia Banks'

Bankruptcy Rate

Gambar 2. Scatterplot hasil uji heteroskedastisitas data

\section{Analisis Regresi Linier Berganda}

Analisis regresi linier berganda adalah hubungan secara linear antara dua atau lebih variabel independen $\left(\mathrm{X}_{1}, \mathrm{X}_{2}, \ldots \mathrm{X}_{\mathrm{n}}\right)$ dengan variabel dependen $(\mathrm{Y})$. Analisis ini untuk mengetahui arah hubungan antara variabel independen dengan variabel dependen apakah masing-masing variabel independen berhubungan positif atau negatif dan untuk memprediksi nilai dari variabel dependen apabila nilai variabel independen mengalami kenaikan atau penurunan. Data yang digunakan biasanya berskala interval atau rasio.

Tabel 10. Nilai Koefisien Hasil Analisis Regresi

\begin{tabular}{|c|c|c|c|}
\hline \multicolumn{2}{|c|}{ Model } & \multicolumn{2}{c|}{ Unstandardized Coefficients } \\
\cline { 3 - 4 } \multicolumn{2}{|c|}{} & B & Std. Error \\
\hline \multirow{4}{*}{1} & (Constant) & 3.431 & 3.309 \\
\cline { 2 - 4 } & LDR & .050 & .028 \\
\cline { 2 - 4 } & NPL & -.780 & .267 \\
\cline { 2 - 4 } & CAR & -.122 & .061 \\
\cline { 2 - 4 } & NIM & .141 & .065 \\
\hline
\end{tabular}

Sumber: Data Primer Diolah

Dari tabel 10 diatas maka dibuat persamaan regresi sebagai berikut:

$$
\mathrm{DA}=3,431+0,050 \mathrm{X} 1-0,780 \mathrm{X} 2-0,122 \mathrm{X} 3+0,141 \mathrm{X} 4
$$

Dari hasil diatas dapat diketahui bahwa variabel LDR (X1), NIM (X4) memiliki pengaruh ke arah positif terhadap tingkat kebangkrutan sedangkan variabel NPL (X2) dan CAR (X3) memiliki pengaruh ke arah negatif terhadap tingkat kebangkrutan pada perbankan syariah.

Adapun interpretasi atas persamaan regresi tersebut dapat dinyatakan sebagai berikut:

1. Nilai konstanta sebesar 3,431 menunjukkan konstanta dari tingkat kebangkrutan (Y) dengan asumsi jika variabel LDR (X1), NPL (X2), CAR (X3) sama dengan nol atau konstan maka nilai tingkat kebangkrutan (Y) mengalami kenaikan sebesar 3,431

2. Koefisien regresi proporsi LDR (X1) sebesar 0,050 menyatakan bahwa setiap perubahan LDR sebesar $1 \%$ maka manajemen laba akan cenderung naik sebesar 0,050 (5,0\%) dengan anggapan bahwa variabel lain, yaitu NPL (X2), CAR (X3), dan NIM (X4). Adanya hubungan yang positif ini, berarti bahwa antara LDR dengan tingkat kebangkrutan laba menunjukkan hubungan yang searah, artinya setiap kenaikan LDR akan cenderung diikuti oleh kenaikan tingkat kebangkrutan bank dan 
Determinants of Sharia Bank's Bankruptcy Rate

122 sebaliknya penurunan LDR cenderung mengakibatkan penurunan tingkat kebangkrutan bank.

3. Koefisien regresi NPL (X2) sebesar -0,780 menyatakan bahwa setiap NPL sebesar 1 maka tingkat kebangkrutan akan cenderung menurun sebesar -0,780 (-78\%) dengan anggapan bahwa variable lain, yaitu LDR (X1), CAR (X3), dan NIM (X4). Adanya hubungan yang negatif ini, berarti bahwa antara NPL dengan tingkat kebangkrutan menunjukkan hubungan yang tidak searah, artinya setiap penurunan NPL akan cenderung diikuti oleh kenaikan tingkat kebangkrutan dan sebaliknya kenaikan NPL cenderung mengakibatkan penurunan tingkat kebangkrutan.

4. Koefisien regresi CAR (X3) sebesar -0,122 menyatakan bahwa setiap perubahan CAR sebesar 1 maka tingkat kebangkrutan akan cenderung turun sebesar 0,122 ($12,2 \%$ ) dengan anggapan bahwa variable lain, yaitu LDR (X1), CAR (X3), dan NIM (X4). Adanya hubungan yang negatif ini, berarti bahwa antara CAR dengan tingkat kebangkrutan menunjukkan hubungan yang tidak searah, artinya setiap penurunan CAR akan cenderung diikuti oleh kenaikan tingkat kebangkrutan bank dan sebaliknya kenaikan CAR cenderung mengakibatkan penurunan tingkat kebangkrutan bank.

5. Koefisien NIM (X4) sebesar 0, 141 menyatakan bahwa setiap perubahan NIM sebesar 1 maka tingkat kebangkrutan bank akan cenderung naik sebesar 0,141 (14,1\%) dengan anggapan bahwa variable lain, yaitu LDR (X1), CAR (X3), dan NIM (X4). Adanya hubungan yang positif ini, berarti bahwa antara NIM dengan tingkat kebangkrutan menunjukkan hubungan yang searah, artinya setiap kenaikan NIM akan cenderung diikuti oleh kenaikan tingkat kebangkrutan dan sebaliknya penurunan NIM cenderung mengakibatkan penurunan tingkat kebangkrutan bank.

\section{Uji Koefisien Determinasi $\left(\mathbf{R}^{2}\right)$}

Uji koefisien determinasi digunakan untuk mengukur seberapa jauh kemampuan model dalam menerangkan variasi variabel independen terhadap variabel dependen. Hasil dari koefisien determinasi dapat dilihat pada tabel 4.28 di bawah ini:

Tabel 11. Nilai Regresi dan Koefisien Determinasi

\begin{tabular}{|c|c|c|c|c|c|}
\hline \multicolumn{6}{|l|}{ Model Summary } \\
\hline Model & $\mathrm{R}$ & R Square & $\begin{array}{c}\text { Adjusted R } \\
\text { Square }\end{array}$ & $\begin{array}{c}\text { Std. Error of the } \\
\text { Estimate }\end{array}$ & $\begin{array}{c}\text { Durbin- } \\
\text { Watson }\end{array}$ \\
\hline 1 & $.649^{\mathrm{a}}$ & .421 & .344 & 1.84227 & .835 \\
\hline
\end{tabular}

a. Predictors: (Constant), NIM, LDR, NPL, CAR

b. Dependent Variable: FC

Dari tabel 11 dapat diketahui bahwa $\mathrm{R}$ Square $\left(\mathrm{R}^{2}\right)$ adalah 0,421 . Hal ini berarti bahwa $42,1 \%$ variabel tingkat kebangkrutan bank (Financial Distress) dapat dijelaskan oleh variabel independen yaitu LDR (X1), NPL (X2), CAR (X3), dan NIM (X4) Sedangkan sisanya sebesar $57,9 \%$ dijelaskan oleh faktor-faktor lain diluar model yang dianalisis.

\section{Uji Signifikansi Simultan (Uji Statistik F)}

Uji pengaruh simultan digunakan untuk mengetahui apakah variabel independen secara bersama-sama atau simultan mempengaruhi variabel dependen. Hasil uji F dalam penelitian dapat dilihat pada tabel di bawah ini:

Tabel 12. Hasil Uji ANOVA

\begin{tabular}{|l|c|c|c|c|c|c|}
\hline \multicolumn{2}{|c|}{ Model } & Sum of Squares & df & Mean Square & F & Sig. \\
\hline \multirow{3}{*}{1} & Regression & 73.972 & 4 & 18.493 & 5.449 & $.002^{\mathrm{b}}$ \\
\cline { 2 - 7 } & Residual & 101.818 & 30 & 3.394 & & \\
\cline { 2 - 7 } & Total & 175.790 & 34 & & & \\
\hline
\end{tabular}

Dari Tabel 12 dapat diketahui bahwa model persamaan ini memiliki tingkat signifikansi, yaitu 0,002 lebih kecil dibandingkan taraf signifikansi $\alpha(0,05)$, maka dapat disimpulkan bahwa variabel independen dalam model penelitian ini secara simultan dapat berpengaruh terhadap variabel dependen yaitu tingkat kebangkrutan. 
Untuk menguji hipotesis maka analisis statistik yang digunakan dalam penelitian ini yaitu regresi linier berganda. Analisis ini digunakan untuk mengetahui besarnya pengaruh variabel independen yaitu LDR,NPL,CAR dan NIM terhadap variabel dependen yaitu tingkat kebangkrutan bank.

\section{Tabel 13. Hasil Uji t}

\begin{tabular}{|c|c|c|c|}
\hline \multicolumn{2}{|c|}{ Model } & $t$ & Sig. \\
\hline \multirow{4}{*}{1} & (Constant) & 1.037 & .308 \\
\cline { 2 - 4 } & LDR & 1.781 & .085 \\
\cline { 2 - 4 } & NPL & -2.920 & .007 \\
\cline { 2 - 4 } & CAR & -1.995 & .055 \\
\cline { 2 - 4 } & NIM & 2.162 & .039 \\
\hline
\end{tabular}

Berdasarkan hasil uji statistik t menunjukkan bahwa dari 4 variabel yang dimasukkan dalam model regresi, hanya variabel NPL , dan NIM yang signifikan mempengaruhi tingkat kebangkrutan bank. Hal ini dapat dilihat dari nilai NPL sebesar 0,007 ( $p<0,05)$, dan NIM sebasar 0,039 $(p<0,05)$. Sedangkan variabel LDR dan CAR ditemukan tidak signifikan. Hal ini terlihat dari nilai LDR secara berurutan sebesar ,085 ( $p>0,05)$ dan CAR sebesar $0,055(p>0,05)$. Jadi dapat disimpulkan bahwa variabel tingkat kebangkrutan bank hanya dipengaruhi oleh variabel NPL dan NIM.

\section{Pembahasan}

Penelitian ini memiliki 5 hipotesis yang diajukan untuk meneliti praktik tingkat kebangkrutan bank syariah di Indonesia. Hasil hipotesis-hipotesis tersebut dijelaskan sebagai berikut.

Hipotesis Pertama (H1) adalah : Diduga ada pengaruh LDR terhadap Tingkat Kebangkrutan Bank. Dari hasil pengujian analisis regresi diperoleh nilai LDR secara berurutan sebesar 0,085 ( $p>0,05)$ LDR tidak berpengaruh secara signifikan terhadap Tingkat Kebangkrutan Bank yang berarti H1 ditolak.

Hipotesis Kedua (H2) adalah diduga ada pengaruh NPL terhadap Tingkat Kebangkrutan Bank. Dari hasil pengujian analisis regresi diperoleh NPL sebesar 0,007 ( $p<0,05)$. maka variabel NPL berpengaruh negatif secara signifikan terhadap tingkat kebangkrutan bank yang berarti $\mathbf{H} \mathbf{2}$ diterima.

Hipotesis Ketiga (H3) adalah diduga ada pengaruh CAR terhadap Tingkat Kebangkrutan Bank. Dari hasil pengujian analisis regresi diperoleh CAR sebesar 0,055 ( $p>0,05)$. Maka variabel CAR tidak berpengaruh secara signifikan terhadap tingkat kebangkrutan Bank yang berarti $\mathbf{H} 3$ ditolak.

Hipotesis Keempat (H4) adalah diduga ada pengaruh NIM terhadap Tingkat Kebangkrutan Bank. Dari hasil pengujian analisis regresi diperoleh NIM sebasar 0,039 (p $<0,05$ ). maka variabel NIM berpengaruh positif secara signifikan terhadap tingkat kebangkrutan bank yang berarti $\mathbf{H} 4$ diterima.

Hipotesis Kelima (H5) adalah diduga ada pengaruh bersama-sama LDR, NPL, CAR, dan NIM terhadap Tingkat Kebangkrutan Bank. Dari hasil pengujian analisis regresi diperoleh nilai F sebesar 0,002 $(p<0,05)$ yang berarti variabel LDR, NPL, CAR dan NIM secara bersama-sama berpengaruh signifikan terhadap tingkat kebangkrutan Bank, yang berarti $\mathbf{H 5}$ diterima.

Penelitian mengenai tingkat kebangkrutan bank telah dilakukan oleh beberapa peneliti dengan menggunakan berbagai variabel. Namun pada beberapa penelitian sebelumnya terdapat ketidakkonsistenan hasil antara yang satu dengan yang lain. Ketidakkonsistenan ini yang menyebabkan adanya research gap dalam penelitian megenai faktor-faktor yang mempengaruhi tingkat bank yang diukur dengan berbagai metode. Restiyana dan mahfud (2016) yang menyatakan hasil bahwa LDR berpengaruh negatif signifikan terhadap tingkat kebangkrutan atau yang sering disebut sebagai financial distress dan Z-Score sebagai alat ukur. Akan tetapi penelitian penulis mengatakan bahwa LDR berpengaruh negatif terhadap tingkat kebangkrutan bank. 
Determinants of Sharia Bank's Bankruptcy Rate

124
Leung, et al (2015) menyatakan hasil penelitiannya bahwa non performing loan berpengaruh positif signifikan terhadap kebangkrutan bank dengan Z-score Index sebagai alat ukur risiko. Namun menurut hasil penelitian Soedarmono, et al (2010) dalam Prasetyo (2013) menyatakan bahwa non performing loan berpengaruh negatif tidak signifikan terhadap tingkat kebangkrutan bank yang diukur dengan SDROA. Penelitian Leung sam dengan hasil penelitian penulis yang NPL berpengaruh positif terhadap tingkat kebangkrutan bank. Penelitian yang dilakukan oleh Soedarmono dan Tarazi (2015) bahwa CAR memiliki pengaruh negatif terhadap signifikan terhadap tingkat kebangkrutan dengan SDROA sebagai alat ukur. Sama dengan penelitian penulis variabel CAR berpengaruh negatif tidak signifikan terhadap tingkat kebangkrutan bank.

Nugroho (2012) hasil pengujian terhadap variabel NIM tidak ditemukan bukti adanya pengaruh NIM terhadap probabilitas kebangkrutan bank di Indonesia karena angka signifikansi sebesar 0.168 . Meskipun NIM tidak berpengaruh secara signifikan terhadap probabilitas kebangkrutan bank di Indonesia namun tanda dari koefisiensinnya telah sesuai dengan hipotesis yang diajukan (negatif). Penelitian ini berbeda dengan penelitian penulis yang menunjukan bahwa NIM berpengaruh positif terhadap tingkat kebangkrutan bank.

\section{PENUTUP}

Dengan melihat hasil penelitian yang telah dibahas, maka dapat kita tarik kesimpilan sebagai berikut:

1. Variabel LDR (X1) tidak berpengaruh signifikan terhadap Tingkat Kebangkrutan Bank.

2. Variabel NPL (X2) mempunyai pengaruh secara signifikan terhadap tingkat kebangkrutan bank dengan tanda negatif hal ini menunjukan bahwa semakin tinggi NPL maka semakin turun nilai Z-Score sehingga meningkatkan tingkat kebangkrutan bank.

3. Variabel CAR (X3) tidak berpengaruh signifikan terhadap tingkat kebangkrutan Bank, terlihat dari nilai 0,055 ( $p>0,05)$ yang berarti CAR berpengaruh negatif tidak signifikan terhadap tingkat kebangkrutan bank.

4. Variabel NIM (X4) berpengaruh signifikan terhadap tingkat kebangkrutan bank dengan tanda positif hal ini menunjukkan bahwa semakin tinggi NIM maka semakin tinggi nilai Z-Score sehingga akan menurunkan tingkat kebangkrutan bank.

5. Variabel LDR,NPL,CAR dan NIM bersama-sama mempunyai pengaruh yang signifikan dan tidak signifikan terhadap tingkat kebangkrutan bank di Perbankan Syariah (BRI Syariah, BTN Syariah, BCA Syariah, Bank Syariah Mandiri, BNI Syariah).

\section{DAFTAR PUSTAKA}

[1] Bank BCA Syariah (2019), Sejarah dan Visi Misi Bank. [tersedia pada:https://www.bcasyariah.co.id] [Diakses pada tanggal 20 September 2019]

[2] Bank BNI Syariah (2019), Sejarah dan Visi Misi Bank. [tersedia pada: www.bnisyariah.co.id] [Diakses pada tanggal 20 September 2019]

[3] Bank BRI Syariah (2019), Sejarah dan Visi Misi Bank. [tersedia pada: www.brisyariah.co.id] [Diakses pada tanggal 20 September 2019]

[4] Bank BTN Syariah (2019), Sejarah dan Visi Misi Bank. [tersedia pada: https://www.syariahbank.com/profil-btn-syariah/] [Diakses pada tanggal 20 September 2019]

[5] Bank Mandiri Syariah (2019), Sejarah dan Visi Misi Bank. [tersedia pada: www.mandirisyariah.co.id] [Diakses pada tanggal 20 September 2019]

[6] Diana, Aan Noor., Syafri, dan Bahtiar Usman (2010). Analisis pengaruh CAR, PPAP, NPM, GCG, BOPO dan LDR terhadap ROA bank yang listing di Bursa Efek Indonesia. Jurnal Ekonomi dan Keuangan, Vol. 2 No. 2, September 2010: 291-298. 
[7] Djanegara, M. S., \& Ivonia, L. (2006). Evaluasi Pengendalian Intern Penjualan Kredit Dalam Meningkatkan Kolektibilitas Piutang pada PT Austindo Nusantara Jaya Finance. Jurnal Umum.

[8] Eng, Tan Sau (2013). Pengaruh NIM, BOPO, LDR, NPL \& CAR terhadap ROA bank internasional dan bank nasional go public periode 2007-2011. Jurnal Dinamika Manajemen, Vol. 1 No. 3, Juni-September 2013:153-167.

[9] Fachrudin, Khaira Amalia. (2008). Kesulitan Keuangan Perusahaan dan Personal. Medan: USU Press.

[10] Fahmi, Irham. (2011). Analisis Laporan Keuangan. Bandung: Alfabeta.

[11] Harjanti, Renny Sri. 2011. Analisis Pengaruh Rasio-Rasio Keuangan Terhadap Prediksi Kebangkrutan Bank (Studi Pada Bank Umum Swasta Devisa yang terdaftar di Bank Indonesia pada tahun 2004-2008), Skripsi Strata-1, Fakultas Ekonomi, Universitas Diponogoro, Semarang.

[12] Iqbal, Mokhamad. 2012. Analisis Prediksi Financial Distress dengan Menggunakan Model Altman Z-Score Modifikasi 1995, Skripsi Strata-1, Universitas Diponegoro, Semarang.

[13] Kajian Pustaka (2018), Financial Distress. [tersedia pada: https://www.kajianpustaka.com/2018/10/financial-distress-kesulitankeuangan.html] [Diakses pada tanggal 20 September 2019]

[14] Keuangan Syariah (2016), Bank-Bank Syariah. [tersedia pada: http://keuangansyariah.mysharing.co/mengenal-jenis-jenis-bank-syariah/ [Diakses pada tanggal [20 September 2019]

[15] Nurhayati, Sri. Wasilah. (2015). Akuntansi Syariah Di Indonesia. Jakarta: Salemba Empat.

[16] Rifa'i Muhammad, Candra Wijaya. 2016. Dasar dasar manajemen. Medan: Perdana Publishing.

[17] Selamet, Riyadi. 2015. Banking Assets And Liability Management, Lembaga Penerbit Fakultas Ekonomi Universitas Indonesia.

[18] Sibarani, Harry. 2010. Prediksi Kebangkrutan Perusahaan Berdasarkan Analisa Model Z-Score Altman pada Perusahaan Makanan dan Minuman yang Terdaftar di Bursa Efek Indonesia (BEI), Skripsi Strata-1, Fakultas Ekonomi, Universitas Sumatera Utara, Medan.

[19] Syaryadi, Fikri. (2012). Pengaruh Rasio Likuiditas Terhadap Financial Distress Perusahaan Industry Tekstil dan Garmen yang Terdaftar di Bursa Efek Indonesia. Jakarta: Digilib.polsri.ac.id.

[20] Warfield,Kieso Weygandts. (2017). Akuntansi Keuangan Menengah. Jakarta; Salemba Empat.

[21] Widyastuti, Astri. 2012. Analisis Z-score dalam Memprediksi Potensi Kebangkrutan Perusahaan Makanan dan Minuman yang Terdaftar di Bursa Efek Indonesia (20082010), Skripsi Strata-1, Fakultas Ekonomi, Universitas Mercu Buana, Jakarta.

[22] Yogi Poltek (2013), Kerangka Konseptual. [tersedia pada: https://yogipoltek.wordpress.com/2013/05/23/kerangka-konseptual/] [Diakses pada tanggal 20 September 2019]

[23] Ferina, V., \& Amrulloh, A. (2020). Analisis Kinerja Keuangan Pada Industri Property dan Real Estate Serta Kontribusinya Terhadap Pendapatan Negara Dari Sektor Pajak. Jurnal Ilmiah Akuntansi Kesatuan, 8(2), 227-236.

[24] Hidayat, L., Muktiadji, N., \& Supriadi, Y. (2020, May). The Knowledge and Students' Interest to Investing in Investment Gallery. In 2nd International Seminar on Business, Economics, Social Science and Technology (ISBEST 2019) (pp. 142-145). Atlantis Press.

[25] Ikhwan, Afiful and Zuhdi, Saefudin and Apriyanto, A. and Irmawati, S. and Weke, Ismail Suardi (2020) Market and Social Collateral Damage of Wuhan Coronavirus. International Journal of Advanced Science and Technology, 29 (6). pp. 1755-1759. ISSN 2207-6360 
Determinants of Sharia Banks' Bankruptcy Rate

[26] Iriyadi, I., Setiawan, B., \& Sutarti, S. (2017). Pelatihan Analisis Data Penelitian (Primer Dan Sekunder) Bagi Mahasiswa Kesatuan. Jurnal Abdimas, 1(1), 1-4.

[27] Irvanto, O., \& Sujana, S. (2020). Pengaruh Desain Produk, Pengetahuan Produk, Dan Kesadaran Merek Terhadap Minat Beli Produk Eiger. Jurnal Ilmiah Manajemen Kesatuan, 8(2), 105-126.

[28] Kusuma, R. D. (2020). Pelatihan Optimasi Media Sosial Untuk Peningkatan Omzet UMKM. Jurnal Abdimas, 4(3), 251-260.

[29] Kusumayanti, D., \& Wibisono, S. (2020). Pendampingan Promosi Digital Bagi UMKM Kota Bogor. Jurnal Abdimas Dedikasi Kesatuan, 1(2), 171-180.

[30] Mulyana, M. (2012). Consumer Behaviour: Sukses Dengan Memahami Konsumen.

[31] Pamungkas, B. (2005). Peranan Internal Audit dalam Meningkatkan Pengendalian Intern Piutang: Studi Kasus pada PT. Vaksindo Satwa Nusantara. Jurnal Ilmiah Ranggagading (JIR), 5(1), 14-21.

[32] Putri, W. W. R., Tartilla, N., \& Pamungkas, M. N. (2020). ANALYSIS OF THE FACTORS THAT AFFECT THE COMPANY'S ACCOUNTING C

[33] Putri, W. W. R., Sudradjat, S., \& Jasmadeti, J. (2020). Analysis Of Factors That Affect The Auditors' Audit Judgment (A Case Study At The Audit Board Of The Republic Of Indonesia BPK RI. Riset, 2(1), 167-180.ONSERVATISM. The Accounting Journal of Binaniaga, 5(2), 101-112.

[34] Rahmat, A., Jasmadeti, J., \& Herawati, H. (2019). Pengaruh Sistem Pengendalian Manajemen Terhadap Peningkatan Performa Proses Kerja Dan Piutang Usaha Pada Perusahaan Pt. Astra International, Tbk-Tso (Studi Kasus Pada Pt Astra International Tbk-Tso Auto2000 Cab. Bogor). Jurnal Ilmiah Manajemen Kesatuan, 7(1), 179-187.

[35] Supriadi, Y., \& Puspitasari, R. (2012). Pengaruh Modal Kerja Terhadap Penjualan dan Profitabilitas Perusahaan: Studi Kasus PT Indocement Tunggal Prakarsa Tbk. Jurnal Ilmiah Kesatuan Nomor, 1.

[36] SYAFITRI, H. W., Nurendah, Y., \& Mashadi, M. (2013). STRATEGI PELAYANAN PADA PENJUALAN SEPEDA MOTOR HONDA PADA PT. SANPRIMA SENTOSA $B O G O R$ (Doctoral dissertation, Institut Bisnis dan Informatika Kesatuan). 